\title{
Phloretin induces apoptosis of human esophageal cancer via a mitochondria-dependent pathway
}

\author{
HONGTAO DUAN ${ }^{1}$, RUIXUAN WANG ${ }^{2}$, XIAOLONG YAN ${ }^{1}$, HONGGANG LIU ${ }^{1}$, \\ YONG ZHANG ${ }^{1}$, DEGUANG MU ${ }^{2}$, JING HAN ${ }^{3}$ and XIAOFEI LI ${ }^{1}$ \\ Departments of ${ }^{1}$ Thoracic Surgery, ${ }^{2}$ Respiration Medicine and ${ }^{3}$ Ophthalmology, \\ Tangdu Hospital, The Fourth Military Medical University, Xi'an, Shaanxi 710038, P.R. China
}

Received January 30, 2016; Accepted December 20, 2016

DOI: $10.3892 / \mathrm{ol} .2017 .7037$

\begin{abstract}
. 2,4,6-trihydroxy-3-(4-hydroxyphenyl)-propiophenone (phloretin) is found in apple tree leaves and the Manchurian apricot, and is a potent compound that exhibits anti-inflammatory, antioxidant and antitumor activities. However, the effect of phloretin on esophageal cancer cells is not well-defined. The present study aimed to examine whether and how phloretin induced apoptosis in human esophageal cancer cells. EC-109 cells were cultured in Dulbecco's modified Eagle's medium and incubated with $60,70,80,90$ and $100 \mu \mathrm{g} / \mathrm{ml}$ phloretin for 6, 12, 24 and $48 \mathrm{~h}$. Cell proliferation was measured by an MTT assay. Cell apoptosis rate was measured using flow cytometric analysis subsequent to propidium iodide (PI) staining. The protein expression levels were determined by western blot analysis. It was found that phloretin significantly decreased viable cell numbers in a dose- and time-dependent manner and induced apoptosis in EC-109 cells. Additionally, phloretin exhibited potent anticancer activity in vitro, as evidenced by the downregulation of the anti-apoptosis-associated molecule B-cell lymphoma 2 (bcl-2) and an increase in the levels of the apoptosis-associated molecules bcl-2-like protein 4 and tumor protein $\mathrm{p} 53$. Phloretin treatment also affected the expression of apoptotic protease activating factor-1, the protein product of the direct binding of the inhibitor of apoptosis protein with low PI to the X-linked inhibitor of apoptosis protein. The present results indicated that phloretin may inhibit EC-109 cell growth by inducing apoptosis, which may be mediated through a mitochondria-dependent pathway.
\end{abstract}

Correspondence to: Professor Xiaofei Li, Department of Thoracic Surgery, Tangdu Hospital, The Fourth Military Medical University, 1 Xinsi Road, Xi'an, Shaanxi 710038, P.R. China

E-mail: 1xffmmu@163.com

Professor Jing Han, Department of Ophthalmology, Tangdu Hospital, The Fourth Military Medical University, 1 Xinsi Road, Xi'an, Shaanxi 710038, P.R. China

E-mail: hanjing.cn@163.com

Key words: phloretin, apoptosis, mitochondria-dependent pathway

\section{Introduction}

Esophageal cancer is the eighth-most common type of cancer globally, and due to the poor prognosis associated with esophageal cancer, it is the sixth most common cause of cancer-associated mortality (1). An estimate indicates that, in 2011, there were 3,372,175 incidences of cancer and 2,113,048 cancer mortalities (2). Histologically, esophageal cancer can be divided into squamous cell carcinoma (SCC) and adenocarcinoma. At present, potential curative treatment options include surgical resection, chemotherapy and chemoradiation. However, as esophageal cancer exhibits few characteristic clinical manifestations, the majority of patients are diagnosed at the advanced stage of the disease (3). In the advanced stages of the disease, the tumor will have already metastasized, and the most important types of treatment are chemotherapy or radiotherapy. Currently, chemotherapy usually comprises of cisplatin and 5-fluorouracil-based therapy, but the increase in survival rate is limited and the 5-year survival rate of esophageal cancer remains low (4). Due to high prevalence rate of esophageal cancer, novel approaches are required to prevent and treat the disease. As a result, attention is being paid at present to numerous phytochemicals that are being explored as potential chemopreventive agents that may reverse or suppress esophageal cancer progression.

Apoptosis is the active process of programmed cell death. Apoptosis depends on an intrinsic apoptotic pathway, which occurs in the mitochondria, or on an extrinsic apoptotic pathway, which involves Fas death receptors (5). The B-cell lymphoma $(\mathrm{Bcl})$ protein family regulates the mitochondrial apoptosis pathway by controlling the permeability of the outer mitochondrial membrane. When the expression of the pro-apoptosis protein $\mathrm{Bcl}-2$-associated $\mathrm{X}$ protein (Bax) is increased, the pro-survival protein $\mathrm{Bcl}-2$ cannot bind to every Bax protein, and thus apoptosis is triggered (6). Apoptosis stimuli increase the level of expression of p53, due to an increase in the permeability of the outer mitochondrial membrane and the release of the apoptotic protease activating factor (APAF-1) and the protein of the direct inhibitor of apoptosis (IAP) binding protein with low PI (Smac/DIABLO) from the mitochondria (7). Subsequent to the binding of cytochrome $c$ and dATP, APAF-1 forms an oligomeric apoptosome. This apoptosome may stimulate the subsequent caspase 
cascade that commits the cell to apoptosis (8). In addition to this, the Smac/DIABLO protein complex inhibits the binding of X-linked inhibitor of apoptosis protein (XIAP) in order to promote apoptosis (9).

2,4,6-trihydroxy-3-(4-hydroxyphenyl)-propiophenone (phloretin), which can be found in apple tree leaves and the Manchurian apricot, is known to exhibit antioxidative, antimicrobial, anti-inflammatory and antitumor properties (10). Phloretin has been shown to exert antitumor activity through the inhibition of protein kinase $\mathrm{C}$ (PKC) activity and the induction of apoptosis (11). The proliferation of the colon cancer HT-29 cells, Fischer bladder cell carcinoma cell lines and Lymphatic tumors have been found to be inhibited by phloretin (12). The effects and anticancer mechanisms of phloretin on esophageal cancer remains unclear. The present study therefore investigated the potential molecular mechanism of phloretin-induced tumor cell apoptosis in EC-109 cells.

\section{Materials and methods}

Cell culture. The esophageal cancer EC-109 cell lines were obtained from the American Type Culture Collection (Manassas, VA, USA). The cell lines were cultured in Dulbecco's modified Eagle's medium (Gibco; Thermo Fisher Scientific, Inc., MA, USA) supplemented with $10 \%$ fetal bovine serum (FBS; Gibco; Thermo Fisher Scientific, Inc.) and $100 \mathrm{mg} / \mathrm{ml}$ penicillin and streptomycin (Invitrogen, Thermo Fisher Scientific, Inc.) in $5 \% \mathrm{CO}_{2}$ at $37.5^{\circ} \mathrm{C}$.

Reagents. Phloretin, purity $>99 \%$, was purchased from Xi'an Plants of Grass Technology Co. Ltd. (Xi'an, China). 3-(4,5-dimethyl-2-thiazolyl)-2,5-diphenyl-2-H-tetrazolium bromide (MTT) was purchased from Sigma-Aldrich (Merck Millipore, Darmstadt, Germany). Benzyloxycarbony (Cbz)l-Val-Ala-Asp (OMe)-fluoromethylketone (Z-VAD-FMK), electrochemiluminescence (ECL), protease inhibitors (phenylmethanesulfonyl fluoride) and phosphatase inhibitors (PhosSTOP) were purchased from Beyotime Institute of Biotechnology (Beijing, China). Antibodies against BAX (\#50599-2-Ig; dilution, 1:500), Bcl-2 (\#12789-1-AP; dilution, 1:600), APAF-1 (\#21710-1-AP; dilution, 1:200), DIABLO (\#10434-1-AP; dilution, 1:1,000), XIAP (\#10037-1-Ig; dilution, 1:400) and p53 (\#10442-1-AP; dilution, 1:700) were purchased from ProteinTech Group, Inc. (Wuhan, China).

Cellular proliferation assay. Cell viability was measured using an MTT assay. A total of $1 \times 10^{4}$ cells were cultured in a 96-well plate and treated with $60-100 \mu \mathrm{g} / \mathrm{ml}$ phloretin for $6,12,24$ or $48 \mathrm{~h}$. In total, $1 \mathrm{mg} / \mathrm{ml}$ of MTT solution (Sigma-Aldrich; Merck Millipore, Darmstadt, Germany) was then added to the medium, and the cells were incubated for an additional $4 \mathrm{~h}$ at $37.5^{\circ} \mathrm{C}$. The medium was then removed, and $100 \mu$ ldimethyl sulfoxide was added to dissolve the solid residue. The absorbance of each well was read at $540 \mathrm{~nm}$ using a micro-ELISA reader. Percent cell survival was defined as the relative absorbance of treated vs. untreated cells.

Cellular apoptosis assay. An Annexin V:PE apoptosis detection kit (Beyotime Institute of Biotechnology) was used to measure the number of apoptotic cells subsequent to the
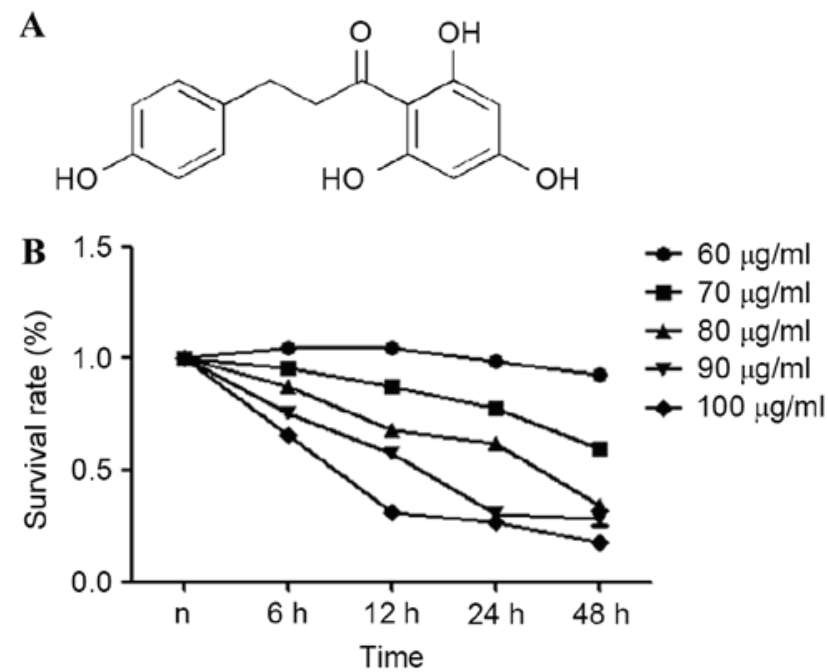

Figure 1. The effect of phloretin, a fruit tree extract, on cell viability. (A) Chemical structure of phloretin. (B) Survival rate of EC-109 cells when treated with phloretin at concentrations ranging from $60-100 \mu \mathrm{g} / \mathrm{ml}$ for 6,12 , 24 and $48 \mathrm{~h}$. The cell viability was quantified using an MTT assay.

cells being treated with phloretin at different concentrations of 60,70 and $80 \mu \mathrm{g} / \mathrm{ml}$ for $12 \mathrm{~h}$. The cells were trypsinized and washed twice with cold PBS, and re-suspended in $1 \%$ bovine serum albumin solution with $5 \mu \mathrm{l}$ Annexin V:PE and $5 \mu 117-\mathrm{AAD}$ at a concentration of $1 \times 10^{5} \mathrm{ml} / \mathrm{cells}$ in a total volume of $100 \mu \mathrm{l}$. The cells were gently mixed, and incubated in the dark for $15 \mathrm{~min}$ at room temperature. A quota of $1 \mu \mathrm{l}$ for Annexin V:PE apoptosis detection kit (\#C1062; Beyotime Institute of Biotechnology) was subsequently added to each test tube and the number of apoptotic cells was quantified by flow cytometry using the BD LSR II Analyzer (BD Biosciences, Franklin Lakes, NJ, USA) within $1 \mathrm{~h}$.

Western blot analysis. The expression levels of the cellular proteins were determined using western blotting assays. The EC-109 cells were treated with $60 \mu \mathrm{g} / \mathrm{ml}$ phloretin for 6, 12 and $24 \mathrm{~h}$. The EC-109 cells were washed with PBS at $4^{\circ} \mathrm{C}$ subsequent to treatment with phloretin, and lysed with $200 \mu \mathrm{l}$ radioimmunoprecipitation assay buffer $(50 \mathrm{mmol}$ 4-(2-hydroxyethyl)-1-piperazineethanesulphoric acid at $\mathrm{pH} 7.5,150 \mathrm{mmol} \mathrm{NaCl}, 10 \%$ glycerol, $1.5 \mathrm{mmol} \mathrm{MgCl} 2,1 \%$ Triton-X 100, 1 mmol EDTA at pH 8.0, 10 mmol sodium pyrophosphate and $10 \mathrm{mmol}$ sodium fluoride) containing a mixture of protease inhibitors (phenylmethanesulfonyl fluoride; 1:100) and a mixture of phosphatase inhibitors (PhosSTOP; 1:40; all, Beyotime Institute of Biotechnology). The present study used the Pierce BCA protein assay kit (Pierce; Thermo Fisher Scientific, Inc.) to measure protein concentrations. Equal amounts of protein samples were electrophoresed on 8-12\% SDS-PAGE mini-gel subsequent to thermal denaturation for $10 \mathrm{~min}$ at $100^{\circ} \mathrm{C}$. The proteins were then transferred onto a polyvinylidene fluoride membrane at $200 \mathrm{~mA}$ for $2 \mathrm{~h}$ at $4^{\circ} \mathrm{C}$. The membranes were probed with the previously indicated antibodies with the previously indicated concentrations overnight at $4^{\circ} \mathrm{C}$, then blotted with a horseradish peroxidase-conjugated cow anti-rabbit secondary antibody (ProteinTech Group, Inc.). Visualization of the membranes was performed using the Bio-Rad ChemiDoc XRS system (Bio-Rad Laboratories, 

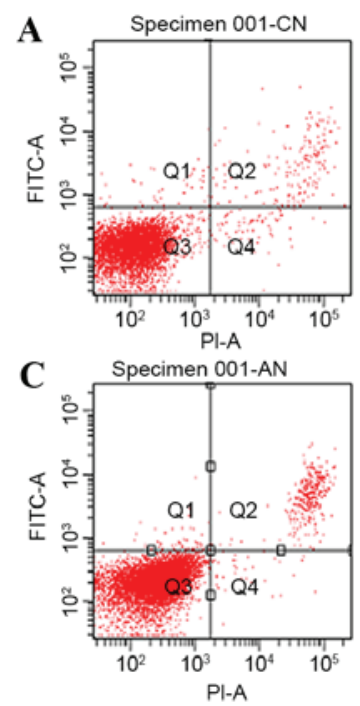
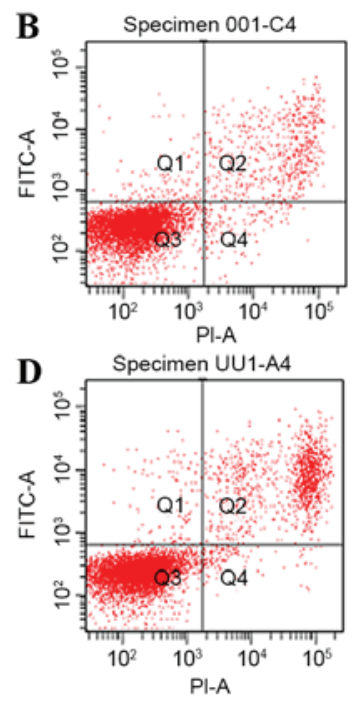

$\mathbf{E}$

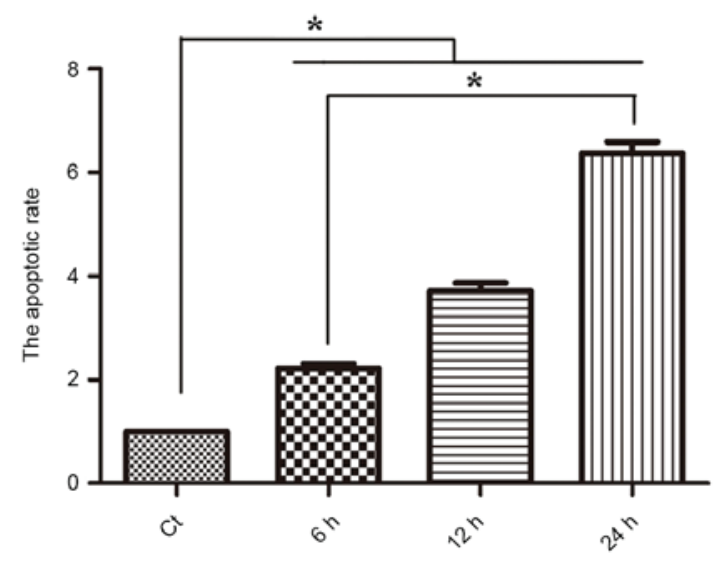

Figure 2. Flow cytometry analysis and histograms. Cell cycle distribution profiles are included for (A) the Ct group and cells treated with phloretin at (B) 60 , (C) 70 and (D) $80 \mu \mathrm{g} / \mathrm{ml}$ for $12 \mathrm{~h}$. (E) A bar graph demonstrating the rate of apoptosis using flow cytometry analysis. Data represent the mean \pm standard deviation of 3 independent experiments. ${ }^{*} \mathrm{P}<0.05$ between indicated groups, unpaired Student's t-test. FITC-A, fluorescein isothiocyanate-A; PI-A, propidium iodide-A, Ct, control.

Inc., Hercules, CA, USA) with ECL (Beyotime Institute of Biotechnology). The western blot was repeated three times, and the blots were quantitatively analyzed using Image Lab 3.0 (Bio-Rad Laboratories, Inc.).

Statistical analysis. All the presented data were confirmed in a minimum of 3 independent experiments, and are expressed as the mean \pm standard deviation. Statistical comparisons were made by unpaired Student's t-test. $\mathrm{P}<0.05$ was considered to indicate a statistically significant difference.

\section{Results}

Phloretin causes dose-dependent and time-dependent growth inhibition in EC-109 cells. Chemical structure of phloretin is presented in Fig. 1A. An MTT assay was used to estimate the effects of phloretin on the viability of the EC-109 cells. From the results obtained, it was demonstrated that the survival rate of the EC-109 cells treated with $60-100 \mu \mathrm{g} / \mathrm{ml}$ phloretin for $6,12,24$ and $48 \mathrm{~h}$ significantly reduced in a dose- and time-dependent manner, as illustrated in Fig. 1B.

Phloretin induces apoptosis in EC-109 cells. Subsequent to the confirmation that the treatment of human esophageal cancer with phloretin resulted in a reduction in cell viability, the present study then investigated whether the effect of phloretin is associated with apoptosis. As revealed in Fig. 2A, flow cytometric analysis suggested that subsequent to treatment with 60,70 and $80 \mu \mathrm{g} / \mathrm{ml}$ phloretin for $12 \mathrm{~h}$, the apoptotic index of the EC-109 cells increased to $225.6 \pm 16.0,375 \pm 24.7$ and $634 \pm 44.6 \%$, respectively $\left({ }^{*} \mathrm{P}<0.05\right.$, compared with the standard control group).

Phloretin induces changes in the expression levels of the $\mathrm{Bcl}$ protein family. Following on from the observation of the regulatory effect of phloretin on the apoptosis in the EC-109 cells, the present study then examined the effect of phloterin on the expression of the key apoptotic regulators Bax and Bcl-2. Fig. 3A provides statistical calculations of the $\mathrm{Bcl}$ protein family expression ratios, demonstrating an increase in the level of Bax, whilst Fig. 3B demonstrates a decline in Bcl-2 levels that consequently led to the increase of the relative rate of Bax/Bcl-2 which evidently occurred in a time-dependent manner.

Phloretin causes an increase in the expression levels of $p 53$. The induction of apoptosis is a key aspect of the tumor-suppressive activity of p53. Fig. 4A demonstrates that treatment with $60 \mu \mathrm{g} / \mathrm{ml}$ phloretin for 6,12 , and $24 \mathrm{~h}$ induced a time-dependent increase in p53 activity, with increases of $178.1 \pm 17.6,249.5 \pm 18.7$ and $261.6 \pm 17.6 \%$ respectively in EC-109 cells ( ${ }^{*} \mathrm{P}<0.05$, compared with the standard control group).

Mitochondrial apoptotic pathways are involved in the anticancer mechanism of phloretin. To investigate the potential underlying mechanism of the proapoptotic activities of phloretin on EC-109 cells, the present study detected changes in the proteins within the mitochondrial apoptotic pathways. Smac/DIABLO and APAF-1, which were located the mitochondrial intermembrane space, were pro-apoptotic with respect to phloretin. Fig. 5A demonstrates that treatment with $60 \mu \mathrm{g} / \mathrm{ml}$ phloretin for 6,12 and $24 \mathrm{~h}$ induced a time-dependent increase in DIABLO activity, with increases of 225.1 \pm 5.6 , $280.5 \pm 15.7$ and $351.6 \pm 17.6 \%$, respectively in EC-109 cells, $(\mathrm{P}<0.05$, compared with the standard control group). Fig. 5B demonstrates that levels of APAF-1 also increased significantly to $160 \pm 9.9,245.5 \pm 15.2$ and $260.4 \pm 10.4 \%$, respectively in the EC-109 cells, subsequent to the different melatonin treatments ( $\mathrm{P}<0.05$, compared with the standard control group). XIAP is a member of the IAP family of proteins and inhibits apoptotic cell death. Fig. 5C demonstrates that subsequent to treatment with $60 \mu \mathrm{g} / \mathrm{ml}$ phloretin for 6,12 and $24 \mathrm{~h}$, a time-dependent decrease in the levels of XIAP was observed in the EC-109 

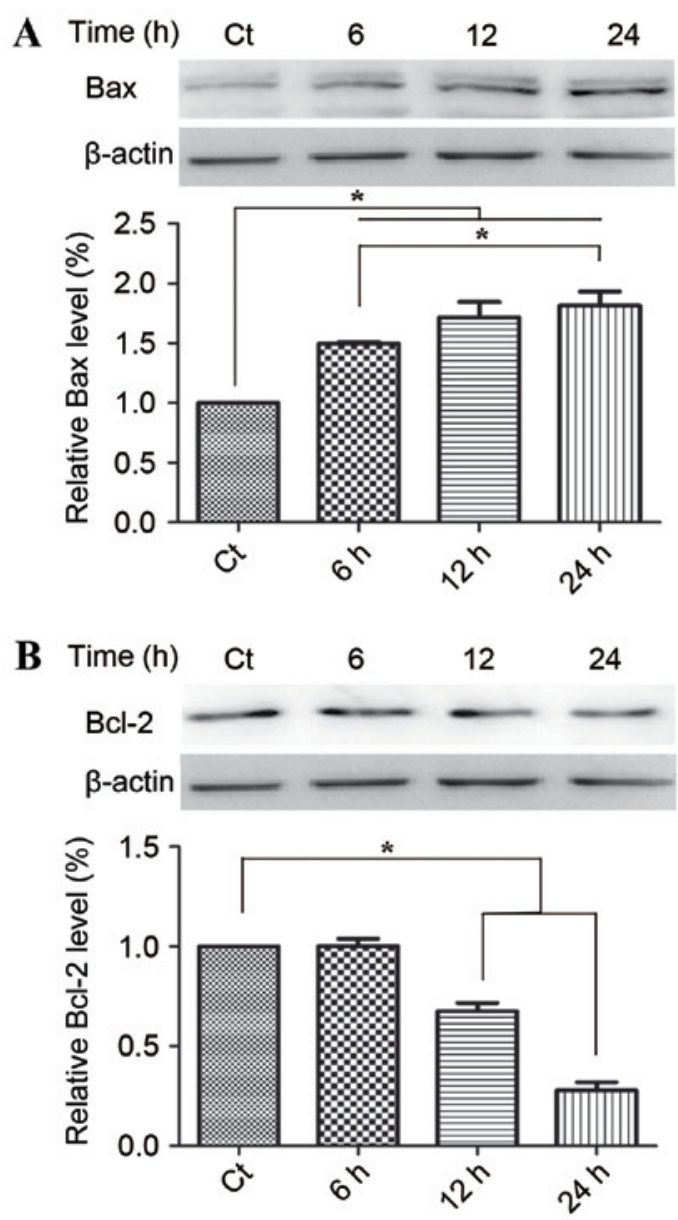

Figure 3. The relative expression level of cells treated with phloretin, as determined by western blot and relative quantification of (A) Bax and (B) $\mathrm{Bcl}-2$. Data represent the mean \pm standard deviation of three independent experiments. ${ }^{*} \mathrm{P}<0.05$ between indicated groups, unpaired Student's t-test. $\mathrm{Ct}$, control; Bax, Bcl-2-associated X protein.

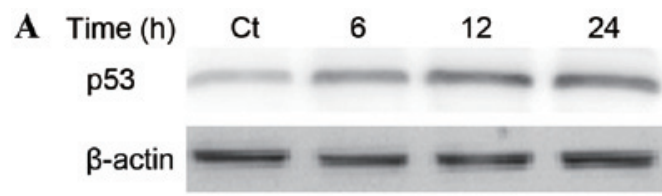

B

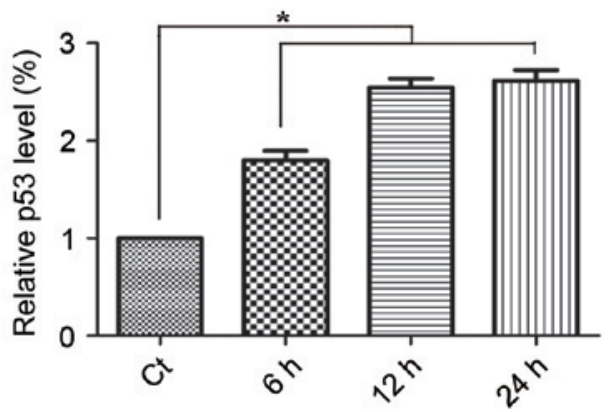

Figure 4. The relative p53 expression level of cells treated with phloretin. (A) Western blotting was used to detect p53. (B) The western blot image was then used for relative quantification. ${ }^{*} \mathrm{P}<0.05$ between indicated groups, unpaired Student's t-test. Ct, control.

cells, with intracellular levels of XIAP measuring 84.3 \pm 4.4 , $75 \pm 7.0$ and $57 \pm 6.4 \%$, respectively $(\mathrm{P}<0.05$, compared with the standard control group).
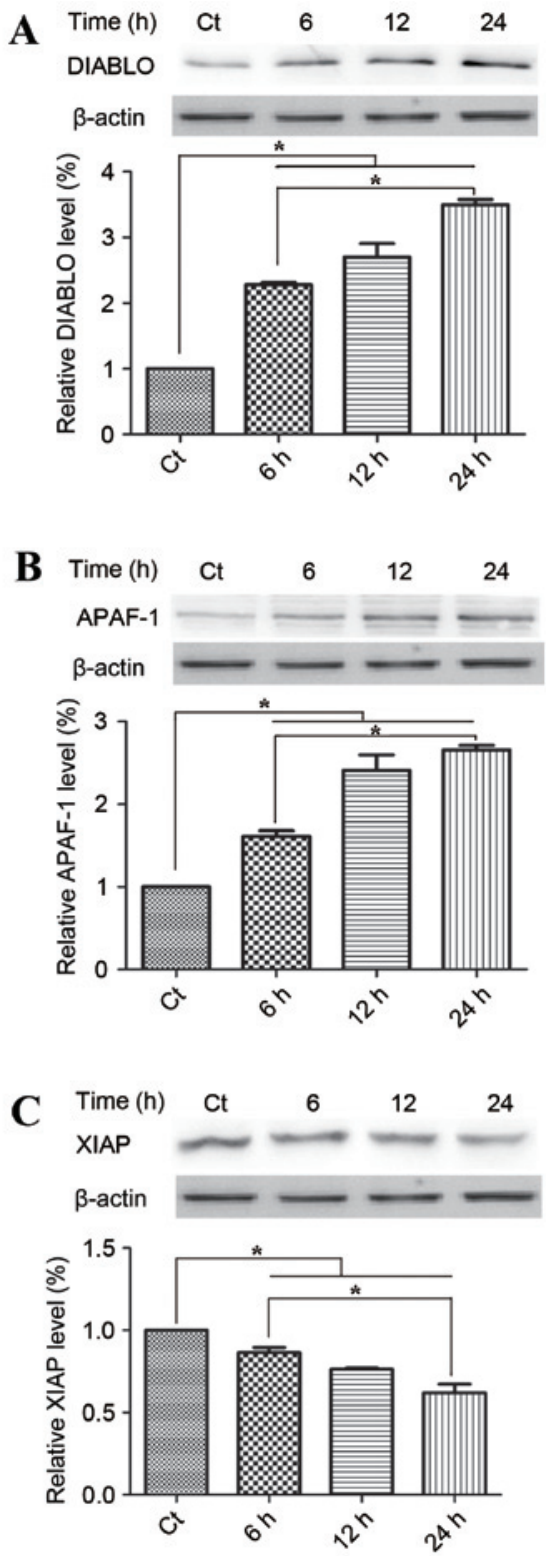

Figure 5. The relative expression level of cells treated with phloretin, as determined by western blot and relative quantification of (A) Smac/DIABLO, (B) APAF-1 and (C) XIAP. ${ }^{*} \mathrm{P}<0.05$ between indicated groups, unpaired Student's t-test. Ct, control; DIABLO (Smac/DIABLO), direct binding protein with low PI; APAF-1, apoptotic protease activating factor 1; XIAP, X-linked inhibitor of apoptosis protein.

\section{Discussion}

In 1993, Nelson and Falk (13) reported that phloretin restricts tumor cell growth by inhibiting glucose transmembrane transport. Furthermore, there is support for the hypothesis that phloretin serves a pivotal role in numerous anticancer mechanisms. Using an MTT assay and flow cytometric analysis, the present study demonstrated that phloretin exhibits antitumor behaviors, including the inhibition of proliferation and the induction of apoptosis. Apoptosis, programmed cell death, is required to maintain homeostasis. Due to decreased rates of apoptosis, tumor cells can survive indefinitely. Several studies have revealed that anticancer drugs induce apoptosis, and thus inhibit the proliferation of the tumor cells $(14,15)$. At present, there are numerous drugs, including drugs targeting the 
caspase family of proteins, which can regulate the apoptotic pathway (16).

The Bcl protein family serves an important role in apoptosis. This family, which is termed due to their different functions and structural homology, may be divided into proapoptotic and antiapoptotic proteins. The antiapoptotic proteins include Bcl-2, Bcl-extra large (Bcl-xL), Bcl-2-like protein $2(\mathrm{Bcl}-\mathrm{w})$ and myeloid leukemia cell differentiation protein (Mcl-1). Equally, proapoptotic proteins include Bax and Bcl-2 homologous antagonist killer (Bak), which can provoke mitochondrial damage and promote cell apoptosis (17). In the present study, western blot analysis revealed that when phloretin stimulated the EC-109 cells, the expression of Bax protein increased, which was accompanied by a decline in the expression of Bcl-2. Under normal circumstances, levels of the pro-apoptosis protein Bax and the anti-apoptosis protein $\mathrm{Bcl}-2$ will maintain the balance of apoptosis. The survival rates of tumor cells depend on the level of $\mathrm{Bcl}-2$ protein present. The expression of $\mathrm{Bcl}-2$ in tumor cells is increased in comparison with the expression of $\mathrm{Bcl}-2$ expression within normal cells. Bcl-2 protects cells from apoptosis, in part due to their ability to bind the Bcl-2 homology $(\mathrm{BH}) 3$-exposed conformers of Bax and Bak, thereby inhibiting full activation of the aforementioned proteins. When the level of Bcl-2 decreases and Bcl-2 cannot bind to Bax, cells will trigger apoptosis. The proapoptotic proteins Bax and Bak serve an important role in the induction of caspase activation (18). Activated Bax inserts into the mitochondrial membrane and increases membrane permeability, leading to an activation of the mitochondrial apoptotic pathway.

p53, as a transcription factor, serves as a tumor suppresser protein and initiates cell death via the mitochondrial apoptotic pathway (19). A previous study revealed that p53 interacts with various members of the $\mathrm{Bcl}$ protein family (20). In the cytosol, p53 forms an inhibitory complex with Bcl-2 to induce cell death, whilst the proapoptotic protein Bax may be directly activated to induce cell death. Activated Bax may form homooligomers, which participate in forming pores and in the control of the permeabilization of the outer mitochondrial membrane, leading to the release of the mitochondrial intermembrane space into the cytosol, including cytochrome $c$, APAF-1 and Smac/DIABLO proteins (21). It has been revealed that when EC-109 cells are treated with phloretin, levels of Smac/DIABLO and APAF-1 increase.

APAF-1, which is assembled into a ring-like platform, is the central component of the apoptosome. In the presence of dATP/ATP, the cytochrome $c$ released from mitochondria interacts with the APAF-1 proteins, initiating the formation of the apoptosome. The apoptosome subsequently begins to recruit pro-caspase-9, and activates the pro-caspases in the intrinsic cell-death pathway, in order to initiate apoptosis via nucleus condensation and/or the degradation of other intracellular structures (22).

Smac/DIABLO is released from the mitochondria, and along with cytochrome $c$, is another important proapoptotic factor. In contrast, XIAP is a member of the IAP family of proteins, and inhibits apoptotic cell death. Smac/DIABLO neutralizes the inhibitory activity of XIAP to promote cytochrome $c$-APAF-1-dependent caspase activation (9). From western blot analyses there is a growing body of evidence indicating that phloretin increases the levels of the proteins p53, APAF-1 and DIABLO, and reduce the levels of XIAP protein to induce apoptosis. Previous studies combined with the results of the present study, have revealed that phloretin increases the levels of apoptosis of EC-109 cells via the mitochondria-apoptotic pathway (23-25).

In conclusion, the present study has reported that phloretin inhibit the proliferation of human esophageal cancer EC-109 cells, and indicated that phloretin exhibits anticancer behavior through the activation of the mitochondrial-apoptosis pathway. In summary, phloretin may be considered to be a promising chemopreventive agent for the treatment of esophageal cancer.

\section{Acknowledgements}

The present study was supported by grants from the National Natural Science Foundation of China (nos. 81200671 and 81172221).

\section{References}

1. Dai T and Shah MA: Chemoradiation in oesophageal cancer. Best Pract Res Clin Gastroenterol 29: 193-209, 2015.

2. Chen W, Zheng R, Zeng H, Zhang S and He J: Annual report on status of cancer in China, 2011. Chin J Cancer Res 27: 2-12, 2015.

3. Raymond DP, Seder CW, Wright CD, Magee MJ, Kosinski AS, Cassivi SD, Grogan EL, Blackmon SH, Allen MS, Park BJ, et al: Predictors of major morbidity or mortality after resection for esophageal cancer: A society of thoracic surgeons general thoracic surgery database risk adjustment model. Ann Thorac Surg 102: 207-214, 2016.

4. Wu XD, Qin HY, Zhang JE, Zheng MC, Xin MZ, Liu L, Wu XJ, Jiang CN and Zhang MF: The prevalence and correlates of symptom distress and quality of life in Chinese oesophageal cancer patients undergoing chemotherapy after radical oesophagectomy. Eur J Oncol Nurs 19: 502-508, 2015.

5. Brunelle JK and Letai A: Control of mitochondrial apoptosis by the Bcl-2 family. J Cell Sci 122: 437-441, 2009.

6. Fletcher JI, Meusburger S, Hawkins CJ, Riglar DT, Lee EF, Fairlie WD, Huang DC and Adams JM: Apoptosis is triggered when prosurvival Bcl-2 proteins cannot restrain Bax. Proc Natl Acad Sci USA 105: 18081-18087, 2008.

7. JI, Dumont P, Hafey M, Murphy ME and George DL: Mitochondrial p53 activates Bak and causes disruption of a Bak-Mcl1 complex. Nat Cell Biol 6: 443-450, 2004.

8. Pop C, Timmer J, Sperandio S and Salvesen GS: The apoptosome activates caspase-9 by dimerization. Mol Cell 22: 269-275, 2006.

9. Wang K and Lin B: Inhibitor of apoptosis proteins (IAPs) as regulatory factors of hepatic apoptosis. Cell Signal 25: 1970-1980, 2013.

10. Yang KC, Tsai CY, Wang YJ, Wei PL, Lee CH, Chen JH, Wu CH and Ho YS: Apple polyphenol phloretin potentiates the anticancer actions of paclitaxel through induction of apoptosis in human hep G2 cells. Mol Carcinog 48: 420-431, 2009.

11. Kim MS, Kwon JY, Kang NJ, Lee KW and Lee HJ: Phloretin induces apoptosis in H-Ras MCF10A human breast tumor cells through the activation of $\mathrm{p} 53$ via JNK and p38 mitogen-activated protein kinase signaling. Ann N Y Acad Sci 1171: 479-483, 2009.

12. Park SY, Kim EJ, Shin HK, Kwon DY, Kim MS, Surh YJ and Park JH: Induction of apoptosis in HT-29 colon cancer cells by phloretin. J Med Food 10: 581-586, 2007.

13. Nelson JA and Falk RE: Phloridzin and phloretin inhibition of 2-deoxy-D-glucose uptake by tumor cells in vitro and in vivo. Anticancer Res 13: 2293-2299, 1993.

14. Haobo L, Guangfeng Z and Xiao Z: OP0216 Resveratrol ameliorates pulmonary fibrosis and inhibits human lung fibroblasts activation VIA modulating SIRT1 and GLI1 signaling. Ann Rheum Dis 74: 152-153, 2015.

15. Yang YC, Lii CK, Lin AH, Yeh YW, Yao HT, Li CC, Liu KL and Chen HW: Induction of glutathione synthesis and heme oxygenase 1 by the flavonoids butein and phloretin is mediated through the ERK/Nrf2 pathway and protects against oxidative stress. Free Radic Biol Med 51: 2073-2081, 2011. 
16. Chan FK and Lenardo MJ: A crucial role for $\mathrm{p} 80$ TNF-R2 in amplifying p60 TNF-R1 apoptosis signals in T lymphocytes. Eur J Immunol 30: 652-660, 2000.

17. Petros AM, Olejniczak ET and Fesik SW: Structural biology of the Bcl-2 family of proteins. Biochim Biophys Acta 1644: 83-94, 2004.

18. Wei MC, Lindsten T, Mootha VK, Weiler S, Gross A, Ashiya M, Thompson CB and Korsmeyer SJ: TBID, a membrane-targeted death ligand, oligomerizes BAK to release cytochrome c. Genes Dev 14: 2060-2071, 2000.

19. Chipuk JE, Kuwana T, Bouchier-Hayes L, Droin NM, Newmeyer DD, Schuler M and Green DR: Direct activation of bax by p53 mediates mitochondrial membrane permeabilization and apoptosis. Science 303: 1010-1014, 2004.

20. Robbins D, Gu X, Shi R, Liu J, Wang F, Ponville J, Mccord JM and Zhao Y: The chemopreventive effects of protandim: Modulation of p53 mitochondrial translocation and apoptosis during skin carcinogenesis. PLoS One 5: e11902, 2010.
21. Du C, Fang M, Li Y, Li L and Wang X: Smac, a mitochondrial protein that promotes cytochrome c-dependent caspase activation by eliminating IAP inhibition. Cell 102: 33-42, 2000.

22. Imao T and Nagata S: Apaf-1- and caspase-8-independent apoptosis. Cell Death Differ 20: 343-352, 2013.

23. Shao X, Bai N, He K, Ho CT, Yang CS and Sang S: Apple polyphenols, phloretin and phloridzin: New trapping agents of reactive dicarbonyl species. Chem Res Toxicol 21: 2042-2050, 2008.

24. Min J, Huang K, Tang H, Ding X, Qi C, Qin X and Xu Z: Phloretin induces apoptosis of non-small cell lung carcinoma A549 cells via JNK1/2 and p38 MAPK pathways. Oncol Rep 34: 2871-2879, 2015.

25. Huang WC, Wu SJ, Tu RS, Lai YR and Liou CJ: Phloretin inhibits interleukin-1 $\beta$-induced COX-2 and ICAM-1 expression through inhibition of MAPK, Akt and NF- $\mathrm{kB}$ signaling in human lung epithelial cells. Food Funct 6: 1960-1967, 2015. 